\title{
Fruit and vegetable consumption in Vietnam, and the use of a 'standard serving' size to measure intake
}

\author{
Tan Van Bui ${ }^{1,2}$, Christopher L. Blizzard ${ }^{1 *}$, Khue Ngoc Luong ${ }^{3}$, Ngoc Le Van Truong 3 , Bao Quoc Tran ${ }^{3}$, \\ Petr Otahal $^{1}$, Velandai Srikanth ${ }^{1,4}$, Mark R. Nelson ${ }^{1}$, Thuy Bich Au${ }^{1}$, Son Thai $\mathrm{Ha}^{3}$, Hai Ngoc Phung ${ }^{1}$, \\ Mai Hoang $\operatorname{Tran}^{1}$, Michele Callisaya ${ }^{1,4}$, Kylie Smith ${ }^{1}$ and Seana Gall ${ }^{1}$ \\ ${ }^{1}$ Menzies Institute for Medical Research, University of Tasmania, Hobart, TAS 7001, Australia \\ ${ }^{2}$ Can Tho University of Medicine and Pharmacy, Can Tho 920000, Vietnam \\ ${ }^{3}$ Medical Services Administration, Ministry of Health of the Socialist Republic of Vietnam, Hanoi 10000O, Vietnam \\ ${ }^{4}$ Department of Medicine, Southern Clinical School, Monash Medical Centre, Monash University, Clayton, VIC 3168, Australia
}

(Submitted 23 May 2015 - Final revision received 17 February 2016 - Accepted 21 March 2016 - First published online 12 May 2016)

\begin{abstract}
The aims of the present study were to provide nationally representative data on fruit and vegetable consumption in Vietnam, and to assess the accuracy of the reported numbers of 'standard servings' consumed. Data analysed were from a multi-stage stratified cluster survey of 14706 participants (46.5\% males, response proportion 64.1\%) aged $25-64$ years in Vietnam. Measurements were made in accordance with the WHO STEPwise approach to surveillance of non-communicable diseases (STEPS) protocols. Approximately $80 \%$ of Vietnamese people reported having less than five servings of fruit and vegetables daily in a typical week. Fruit and vegetable intake reported in 'standard serving' sizes was positively correlated with levels of education completed and household income $(P<0 \cdot 001$ for trend). The correlations between summary values for each province reflect some known demographic, geographical and climatic characteristics of the country. For example, provinces at higher latitude had higher mean servings of vegetables $(r 0.90)$, and provinces with higher proportions of urban population had higher mean servings of fruit $(r$ 0.40). In conclusion, about eight in ten Vietnamese people aged $25-64$ years did not meet WHO recommendations for daily consumption of at least five servings of fruit and vegetables. On the basis of the consistency of the data collected with other estimates and with physical and demographic characteristics of the country, the WHO STEPS instrument has construct validity for measuring fruit and vegetable intake, but with two issues identified. The issues were seasonal variation in reporting and a limitation on the usefulness of the information for associative analyses.
\end{abstract}

\section{Key words: Fruit and vegetable consumption: Self-report: Standard serving sizes: BMI: Validation}

Low fruit and vegetable consumption was among the top 20 risk factors contributing to the global burden of disease in $2010^{(1)}$. Inadequate intake of fruit and vegetables was estimated to be responsible for nearly $14 \%$ of gastrointestinal cancer, $11 \%$ of ischaemic heart disease, $9 \%$ of stroke deaths and approximately $3 \%$ of overall mortality worldwide ${ }^{(2)}$. Global data show that more than three-quarters of the world population consume less than the WHO recommendation of at least five servings of fruit and vegetables per day ${ }^{(3)}$. Rapid urbanisation, rising incomes and an increase in fast food consumption have reportedly led to a decreased consumption of fruit and vegetables in developing countries $^{(4)}$.

Common methods used to assess food consumption include dietary records, 24-h dietary recall, FFQ and dietary history ${ }^{(5,6)}$. However, using these instruments can be time-consuming and unwarranted in situations that do not require assessment of the total diet. Many brief dietary instruments for assessments of specific dietary components, such as fruit and vegetables, have been developed for use in population surveillance to monitor national and regional trends in consumption over time, and to evaluate interventions intended to modify intake for the primary prevention of chronic diseases ${ }^{(5,6)}$. Brief questions have been shown to provide a valid measure of fruit and vegetable intake ${ }^{(7)}$. Two simple questions on fruit and vegetable consumption were used in the World Health Survey ${ }^{(3)}$, and four simple questions were included in the "WHO STEPwise approach to surveillance of non-communicable diseases (NCD)' (STEPS) questionnaire to collect information on the number of standard servings of fruit and vegetables per day in a typical week ${ }^{(8)}$. A 'standard serving' size was used to standardise measurement because validation studies of brief instruments in the USA suggested that actual fruit and vegetable intake was underestimated without portion size adjustments $^{(9-11)}$

Abbreviation: STEP, STEPwise approach to surveillance of non-communicable diseases.

* Corresponding author: C. L. Blizzard, fax +61 36226 7704, email Leigh.Blizzard@utas.edu.au 
In Vietnam, information on fruit and vegetable intake has been reported in a national nutrition survey ${ }^{(12)}$ conducted during 2009/2010 using the 24-h recall method. The STEPS questionnaire has been used to collect fruit and vegetable data in studies conducted in the cities of Hanoi ${ }^{(13)}$ and Can Tho ${ }^{(14)}$ in 2005, but the validity of this instrument has not been tested.

Taking advantage of the data from a nationally representative survey of NCD risk factors, the principal aim of this study was to provide national estimates of fruit and vegetable consumption in Vietnam. The secondary aim was to investigate whether or not the four simple questions used to measure fruit and vegetable intake reported in 'standard serving' sizes have evidence of construct validity.

\section{Methods \\ Study design and participants}

The data used for this analysis were from a population-based survey of risk factors for NCD in Vietnam in 2009/2010 that was designed in accordance with the STEPS methodology ${ }^{(8)}$. Eligible subjects were persons aged 25-64 years living at a residential address in each selected commune, town or city ward of eight provinces (Thai Nguyen, Hòa Bình, Hanoi, Hue, Binh Dinh, Đak Lak, Ho Chi Minh City and Can Tho), each representative of one of the eight geographical regions of Vietnam. The two-stage sampling procedure involved selecting twenty clusters (communes, towns and city wards) from each of the eight geographically representative provinces with probabilities proportional to population size from four strata defined by urban-rural location and rich-poor classification. For each selected cluster, the provincial health authority prepared a comprehensive listing of residents aged 25-64 years. From those lists, persons were selected by age and sex-stratified random sampling. Of the 22940 eligible subjects aged 25-64 years, 14706 participated (response proportion 64.1\%). The details have been presented elsewhere ${ }^{(15)}$. The protocol of this survey was approved by the Ethics Committee of the Vietnam Ministry of Health and the Tasmanian Health and Medical Human Research Ethics Committee. Informed consent was obtained from participants.

\section{Measurements}

Information on fruit and vegetable consumption was collected using four simple questions included in the WHO STEPS questionnaire $^{(8)}$. The questionnaire was translated into Vietnamese and back-translated by independent translators to ensure that the appropriate meaning of each item was retained. Face-to-face interviews were conducted with participants by trained staff of each provincial health authority. The participants were asked about the number of days they usually ate fruit, and the number of days they usually ate vegetables (excluding root plants), in a typical week and how many 'standard serving' sizes they usually ate of each on those days. A 'standard serving' size of vegetables was defined as a cup of raw vegetables, a half cup of cooked or chopped raw vegetables or half cup of vegetable juice. A 'standard serving' size of fruit was defined as a piece of whole of fruit, a half cup of cooked, chopped or processed fruit or half cup of fruit juice. These quantities are assumed to correspond to $80 \mathrm{~g}^{(8)}$. For translation in field work, we referred to bowls of the type commonly used in Vietnam rather than cups. Visual aids (show-cards) depicting a 'standard serving' size of twelve different types of fruit and seventeen different vegetables were used to facilitate interviewing ${ }^{(8)}$. Measurements of socio-demographic characteristics, other behavioural risk factors and body size/fatness, including weight, height, and waist and hip circumference, were made according to the standardised STEPS procedures ${ }^{(8)}$. BMI was calculated as weight height ${ }^{2}$ and categorised as under-weight, normal weight, overweight and obese according to cut-off points for Asian populations ${ }^{(16)}$.

\section{Data analysis}

The daily consumption of fruit and vegetables was estimated separately for fruit and for vegetables by multiplying the typical weekly frequency of consumption of fruit and vegetables by the number of servings consumed per day and dividing it by seven. Low fruit and vegetable intake was defined as consuming less than five servings of fruit and vegetables per day ${ }^{(8)}$. Nonmissing data were re-weighted to account for missing data ${ }^{(17)}$.

For individual-level analyses, linear regression was used to estimate adjusted means of standard servings of fruit and vegetables consumed, and Poisson regression with robust standard errors ${ }^{(18)}$ was used to estimate adjusted prevalence and ratios of prevalence of having at least five servings at different levels of socio-demographic factors. Tests of trend were undertaken by replacing multiple binary $(0 / 1)$ covariates for the socio-demographic factors with a single ordinal covariate. Partial Pearson's correlation coefficients were used to assess the associations between fruit/vegetable intake and body size/ fatness. Age, income and alcohol consumption were adjusted for in each analysis. Other factors investigated as potential confounders were education, tobacco smoking and physical activity. $\chi^{2}$ Analysis was used to compare distributions of fruit and vegetable intake. The analyses were performed using complex survey methods provided by Stata version 12.0.

At the aggregate level, Pearson's correlation coefficients were used to summarise the associations between aggregate measures of fruit and vegetable consumption for each province (e.g. the provincial proportions of persons meeting the WHO recommendations for consuming at least five servings of fruit and vegetables daily) ${ }^{(19)}$ and its demographic, geographical and climatic characteristics (including the proportion of each provincial population living in areas classified as urban). Wet season and dry season were defined as months with average rainfall $>60 \mathrm{~mm}$ and $\leq 60 \mathrm{~mm}$, respectively ${ }^{(20)}$.

Construct validity of the STEPwise approach to surveillance of non-communicable diseases questionnaire for measuring fruit and vegetable intake

Construct validity is the degree to which a measured quantity represents the theoretical construct that it purports to measure. Its evaluation requires examination of correlations of the measure with other quantities that are known, or are expected 
on theoretical grounds, to be related to the construct. In this study, the collected data were used as the reference for verifying the construct validity. To do this, we required our national estimates to be consistent with other estimates for Vietnam and generally similar to estimates for other countries of the region, our provincial estimates to reflect climatic conditions (average monthly rainfall and temperature) that favour vegetable growing in the north and rice growing in the south and to have a seasonal pattern (dry and wet) mirroring the harvest cycle and our individual-level estimates to vary directly with markers of availability (urban and rural areas) of and capacity (monthly household income) to pay for fruit and vegetables and inversely with health-related indicators of poor diet (body size and fatness).

\section{Results}

\section{Characteristics of the sample}

Table 1 presents selected characteristics of participants, stratified by sex. Approximately $70 \%$ of the sample lived in rural areas. Men had higher proportions of high-school completions, and were more active than women. Three in four men were tobacco smokers and two in five were hazardous/harmful drinkers. These behaviours were rare among women. However, mean levels of BMI, waist circumference, waist:hip ratio (WHR), number of days when respondents consumed fruit and vegetables, number of daily servings of fruit, vegetables and fruit and vegetables combined, and the proportions of participants meeting the WHO recommendations were generally similar between men and women. Both men and women consumed vegetables almost every day in a typical week, whereas fruit was consumed on only $3.2 \mathrm{~d}$ (men) and $4.0 \mathrm{~d}$ (women). On average, approximately 0.9 servings of fruit and 2.3 servings of vegetables were consumed daily, with no meaningful differences across sexes. Participants living in the northern provinces (Thai Nguyen, Hòa Bình and Hanoi) had significantly higher intake of vegetables, and of fruit and vegetables combined, than did those in the southern provinces (Ho Chi Minh City and Can Tho) (online Supplementary Table S1).

Estimated proportions of the Vietnamese population meeting the daily recommended intake levels of fruit and vegetables are depicted in Fig. 1. The proportions of respondents having daily consumption of at least two servings of fruit and three servings of vegetables were 16.7 and $32.2 \%$, respectively. In all, $<20 \%$ of respondents reported having at least five servings of fruit and vegetables per day in a typical week. These estimates were similar for men and women (data not shown). The frequency distribution of the number of servings of fruit and of vegetables in each region of the country was similar for men and women. Online Supplementary Fig. S1 shows this for fruit and vegetable consumption in the three northern-most and two southern-most provinces. The differences by sex for each food type (fruit, vegetables) and in each region are statistically significant $(P<0.001)$ in this large sample, but they are less pronounced than the differences between food types and regions, and in most cases were minor and not statistically significant within strata of BMI, indicating that men and women with the same body size in each region ate similar quantities of fruit and vegetables.
Table 1. Characteristics of subjects

(Weighted percentages and unweighted number in this category/unweighted total number; mean values and standard deviations)

\begin{tabular}{|c|c|c|c|c|}
\hline \multirow[b]{2}{*}{ Characteristics } & \multicolumn{2}{|r|}{ Men } & \multicolumn{2}{|c|}{ Women } \\
\hline & $\%$ & $n / N$ & $\%$ & $n / N$ \\
\hline \multicolumn{5}{|l|}{ Age (years) } \\
\hline Mean & \multicolumn{2}{|r|}{$40 \cdot 5$} & \multicolumn{2}{|r|}{$41 \cdot 1$} \\
\hline SD & \multicolumn{2}{|r|}{$10 \cdot 2$} & \multicolumn{2}{|r|}{$10 \cdot 5$} \\
\hline Minority ethnicity (Non-Kinh) & $5 \cdot 8$ & $1161 / 6787$ & $5 \cdot 4$ & $1283 / 7889$ \\
\hline Rural residential area & $70 \cdot 2$ & $4434 / 6804$ & $69 \cdot 2$ & $5079 / 7902$ \\
\hline \multicolumn{5}{|l|}{ Education completed } \\
\hline Less than high school & $71 \cdot 0$ & $4929 / 6785$ & 75.9 & $6213 / 7885$ \\
\hline High school+ & $29 \cdot 0$ & $1856 / 6785$ & $24 \cdot 1$ & $1672 / 7885$ \\
\hline \multicolumn{5}{|l|}{ Monthly household income* } \\
\hline$<20$ USD & $15 \cdot 4$ & $1214 / 5803$ & 14.9 & $1479 / 6595$ \\
\hline 20-39 USD & $20 \cdot 9$ & $1452 / 5803$ & $22 \cdot 2$ & $1641 / 6595$ \\
\hline 40-59 USD & $23 \cdot 4$ & $1164 / 5803$ & $22 \cdot 7$ & $1322 / 6595$ \\
\hline 60-79 USD & 8.5 & $514 / 5803$ & $8 \cdot 1$ & $523 / 6595$ \\
\hline 80+ USD & $31 \cdot 8$ & $1459 / 5803$ & $32 \cdot 1$ & $1630 / 6595$ \\
\hline \multicolumn{5}{|l|}{ Smoking status } \\
\hline Never smoker & $25 \cdot 1$ & $1723 / 6782$ & $97 \cdot 4$ & $7551 / 7886$ \\
\hline Ex-smoker & $17 \cdot 2$ & $1347 / 6782$ & 0.9 & $101 / 7886$ \\
\hline Current non-daily smoker & $2 \cdot 8$ & $166 / 6782$ & 0.1 & $12 / 7886$ \\
\hline Current daily smoker & $54 \cdot 9$ & $3546 / 6782$ & 1.7 & $222 / 7886$ \\
\hline \multicolumn{5}{|l|}{ Alcohol consumption $†$} \\
\hline Low & $59 \cdot 3$ & $4147 / 6804$ & $97 \cdot 4$ & $7643 / 7902$ \\
\hline Hazardous & $16 \cdot 6$ & $1104 / 6804$ & $1 \cdot 8$ & 189/7902 \\
\hline Harmful & $24 \cdot 1$ & $1553 / 6804$ & 0.9 & 70/7902 \\
\hline \multicolumn{5}{|l|}{ Physical activity $¥$} \\
\hline Low & $27 \cdot 2$ & $1435 / 6786$ & $31 \cdot 1$ & $1811 / 7878$ \\
\hline Moderate & $20 \cdot 8$ & $1298 / 6786$ & $27 \cdot 8$ & $1937 / 7878$ \\
\hline High & $52 \cdot 0$ & $4053 / 6786$ & $41 \cdot 1$ & $4130 / 7878$ \\
\hline \multicolumn{5}{|l|}{ Fruit intake } \\
\hline \multicolumn{5}{|l|}{ Days per week } \\
\hline Mean & & 3.4 & & $4 \cdot 0$ \\
\hline SD & & 2.5 & & 2.5 \\
\hline \multicolumn{5}{|l|}{ Servings per day } \\
\hline Mean & & 0.8 & & 0.9 \\
\hline SD & & 0.9 & & 0.9 \\
\hline \multicolumn{5}{|l|}{ Vegetable intake } \\
\hline \multicolumn{5}{|l|}{ Days per week } \\
\hline Mean & & $6 \cdot 2$ & & $6 \cdot 4$ \\
\hline SD & & $1 \cdot 7$ & & 1.5 \\
\hline Servings per day & & & & \\
\hline Mean & & $2 \cdot 3$ & & $2 \cdot 3$ \\
\hline SD & & 1.6 & & $1 \cdot 4$ \\
\hline Fruit and vegetable intake & & & & \\
\hline Servings per day & & & & \\
\hline Mean & & $3 \cdot 2$ & & $3 \cdot 2$ \\
\hline SD & & $2 \cdot 0$ & & 1.9 \\
\hline$\geq 5$ servings/d & $18 \cdot 3$ & $1117 / 6708$ & $18 \cdot 2$ & $1416 / 7816$ \\
\hline Body size and fatness & & & & \\
\hline BMI $\left(\mathrm{kg} / \mathrm{m}^{2}\right)$ & & & & \\
\hline Mean & & 21.5 & & $21 \cdot 5$ \\
\hline SD & & $3 \cdot 1$ & & $3 \cdot 0$ \\
\hline Waist (cm) & & & & \\
\hline Mean & & $74 \cdot 9$ & & $72 \cdot 0$ \\
\hline $\mathrm{SD}$ & & $8 \cdot 9$ & & $8 \cdot 6$ \\
\hline Waist:hip ratio & & & & \\
\hline Mean & & 0.9 & & 0.8 \\
\hline SD & & 0.1 & & 0.1 \\
\hline
\end{tabular}

MET, metabolic equivalent.

* Monthly household income per adult member (USD).

† Hazardous drinking: $\geq 4$ standard drinks (men) and $\geq 2$ standard drinks (women) per drinking occasion during the last year; harmful drinking: $\geq 6$ standard drinks (men) and $\geq 4$ standard drinks (women) per drinking occasion during the last year.

‡ Low: <600 MET-min/week; moderate: 600 - 3000 MET-min/week; high: >3000 MET$\mathrm{min} /$ week. 


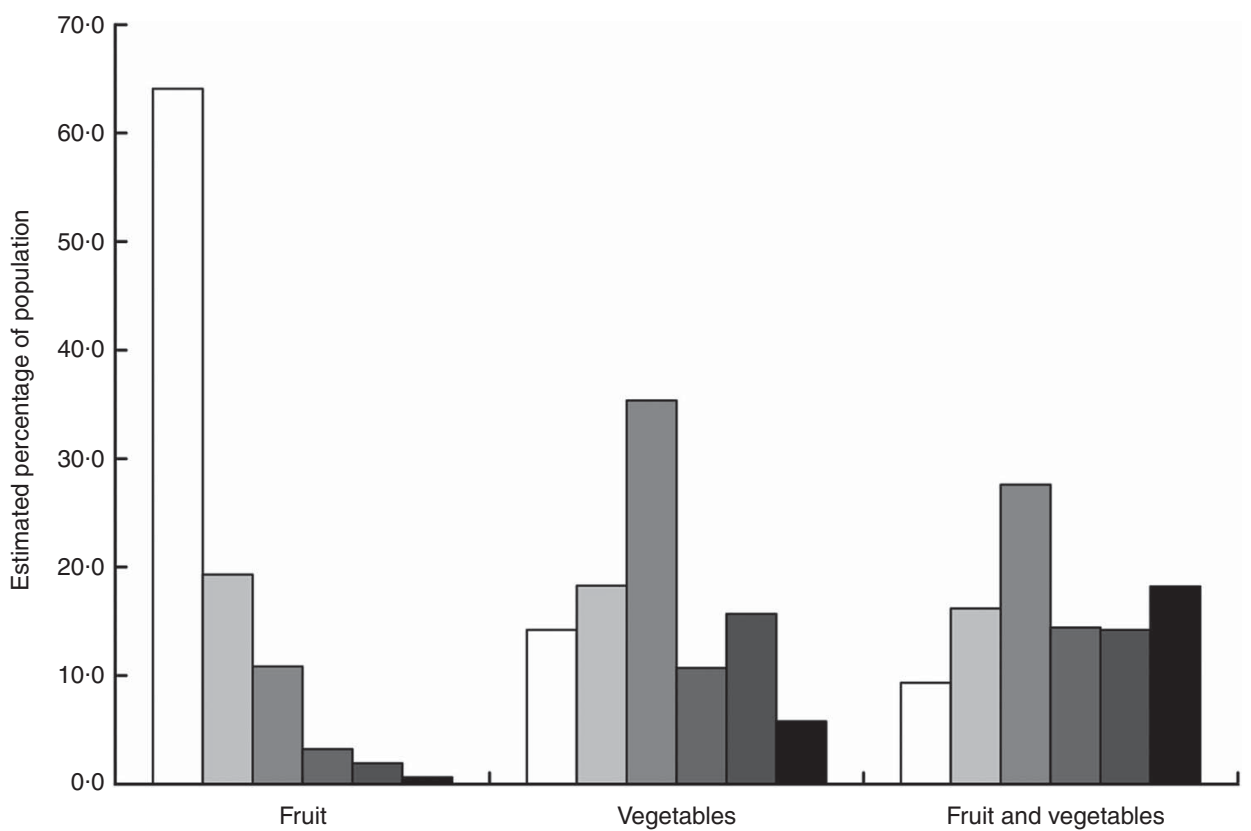

Fig. 1. Estimated proportions of the Vietnamese population consuming fruit and vegetables per $d$ in a typical week. $\square,<1$ serve; $\square, 1-1.9$ serves; $\square, 2-2.9$ serves; $\square$, 3-3.9 serves; $\square, 4-4.9$ serves; $\square, 5+$ serves.

\section{Individual-level analyses}

Table 2 presents estimated associations between fruit and vegetable consumption and socio-demographic factors. Overall, respondents with higher levels of education and household income, and those living in urban areas, reported more consumption of fruit and of vegetables than those living in rural areas. Educational status, household income and residential area independently predicted both fruit consumption and vegetable consumption (online Supplementary Table S3).

Estimated associations of fruit and vegetable intake with body size/fatness are presented in Table 3. Consumption of fruit, vegetables or fruit and vegetables combined was positively and significantly correlated with BMI, waist circumference and WHR for both men and women. There were stronger correlations of fruit and vegetable indicators with body size/fatness for women. Rank correlation coefficients were generally similar to Pearson's correlation coefficients (data not shown).

\section{Aggregate-level analyses}

The correlations between summary values of fruit/vegetable indicators and socio-demographic, geographical and climatic factors of each province are summarised in Table 4. Provincial mean servings of fruit, vegetables and fruit plus vegetables were correlated with proportions of urban population and with the latitude and climate of each province. The relatively low vegetable consumption and relatively high fruit consumption in the highly urbanised southern-most provinces of Can Tho and Ho Chi Minh City, and the relatively high vegetable consumption in the more temperate northern provinces (Thai Nguyen, Hanoi and Hòa Bình), were influential in producing these associations. They are depicted in online Supplementary Fig. S2.
The summary values were inversely associated with the proportion of respondents interviewed in the wet season. This brought into question the seasonal timing of the survey. Overall, $92 \cdot 1 \%(12924 / 14706)$ of respondents were interviewed in the wet season. For five provinces, we were able to compare fruit/ vegetable intake for those interviewed in the wet season and those in the same province interviewed in the dry season. The proportions of interviews conducted in the wet season for Hòa Bình, Hanoi, Binh Dinh, Đak Lak and Can Tho were $97 \cdot 0 \%$ (1758/1902), 93.8\% (1566/1643), 45.6\% (772/1911), $88.8 \%$ (1509/1809) and $90 \cdot 3 \%(1592 / 1714)$, respectively. The mean servings of fruit in these five provinces were 0.83 (wet season) and 0.80 (dry season) $(P=0 \cdot 249)$. The mean servings of vegetables were 2.29 (wet season) and 2.09 (dry season) $(P=0.007)$. The results of re-scaling the dry season values for fruit/vegetables to have the same median in each age, sex and urban/ rural stratum as the wet season values are shown in the online Supplementary Table S2. The impacts were negligible on the national estimates, but of consequence for the estimates for provinces in which respondents were interviewed in the dry season.

\section{Discussion}

One of the main findings of the present study is that Vietnamese people consume on average 0.87 servings of fruit and 2.29 servings of vegetables/d, with $<20 \%$ of Vietnamese people aged 25-64 years meeting the WHO recommendations for a daily consumption of at least five standard servings of fruit and vegetables. The overall findings are broadly consistent with previous studies $^{(12,21)}$. Our mean servings of fruit and of vegetables were a little higher than, but generally similar to, the results of a national nutrition survey conducted in Vietnam 
Table 2. Factors associated with mean daily servings of fruit and vegetables and with the proportion of the population having at least five servings of fruit and vegetables per day

(Mean values and $95 \%$ confidence intervals; weighted percentages and unweighted number of respondents/total number of respondents in this category; prevalence ratio (PR) and $95 \%$ confidence interval)

\begin{tabular}{|c|c|c|c|c|c|c|c|c|}
\hline & \multicolumn{2}{|c|}{ Fruit } & \multicolumn{2}{|c|}{ Vegetables } & \multicolumn{4}{|c|}{$\geq 5$ servings ${ }^{*}$} \\
\hline & Mean & $95 \% \mathrm{Cl}$ & Mean & $95 \% \mathrm{Cl}$ & $\%$ & $n / N$ & PR & $95 \% \mathrm{Cl}$ \\
\hline \multicolumn{9}{|l|}{ Men } \\
\hline \multicolumn{9}{|l|}{ Age group } \\
\hline $25-34$ years & 0.85 & $0.77,0.93$ & $2 \cdot 31$ & $2 \cdot 19,2.42$ & 17.6 & $225 / 1406$ & 1.00 & \\
\hline $35-44$ years & 0.81 & $0.74,0.89$ & $2 \cdot 36$ & $2.25,2.47$ & 19.7 & $295 / 1643$ & 1.12 & $0.88,1.42$ \\
\hline $45-54$ years & 0.78 & $0.72,0.84$ & $2 \cdot 34$ & $2 \cdot 21,2.47$ & $17 \cdot 6$ & $285 / 1769$ & 1.00 & $0.78,1.28$ \\
\hline $55-64$ years & 0.83 & $0.76,0.90$ & $2 \cdot 24$ & $2 \cdot 14,2 \cdot 35$ & $17 \cdot 8$ & $312 / 1890$ & 1.01 & $0.80,1.28$ \\
\hline $\begin{array}{l}P_{\text {trend }} \\
\text { Ethnicityt }\end{array}$ & \multicolumn{2}{|c|}{0.321} & \multicolumn{2}{|c|}{0.787} & & & \multicolumn{2}{|r|}{0.983} \\
\hline Kinh & 0.82 & $0.77,0.86$ & $2 \cdot 32$ & $2 \cdot 25,2 \cdot 38$ & 18.2 & $944 / 5551$ & 1.00 & \\
\hline Non-Kinh & 0.91 & $0.76,1.06$ & 2.52 & $2 \cdot 23,2 \cdot 81$ & $19 \cdot 7$ & $169 / 1140$ & \multirow{2}{*}{\multicolumn{2}{|c|}{0.551}} \\
\hline$P$ & \multicolumn{2}{|c|}{0.243} & \multicolumn{2}{|c|}{0.176} & & & & \\
\hline \multicolumn{9}{|l|}{ Residential areas $†$} \\
\hline Urban & 0.94 & $0.88,0.99$ & $2 \cdot 28$ & $2 \cdot 18,2 \cdot 37$ & $20 \cdot 9$ & $478 / 2344$ & 1.00 & \\
\hline Rural & 0.77 & $0.72,0.83$ & $2 \cdot 34$ & $2.27,2.42$ & $17 \cdot 1$ & $639 / 4364$ & 0.82 & $0.70,0.96$ \\
\hline$P$ & \multicolumn{2}{|c|}{$<0.001$} & \multicolumn{2}{|c|}{0.289} & & & \multicolumn{2}{|r|}{0.013} \\
\hline Education levels $†$ & & & & & & & & \\
\hline$<$ Primary & 0.62 & $0.51,0.72$ & 1.96 & $1.85,2.08$ & $11 \cdot 1$ & $102 / 1021$ & 1.00 & \\
\hline Primary & 0.71 & $0.64,0.78$ & $2 \cdot 21$ & $2 \cdot 07,2.35$ & $15 \cdot 4$ & $225 / 1802$ & 1.39 & $0.94,2.06$ \\
\hline Secondary & 0.83 & $0.76,0.89$ & $2 \cdot 28$ & $2 \cdot 17,2.39$ & $16 \cdot 7$ & $335 / 2026$ & 1.51 & $1.13,2.01$ \\
\hline Senior secondary & 0.94 & $0.85,1.04$ & 2.50 & $2 \cdot 32,2.68$ & $21 \cdot 3$ & $187 / 933$ & 1.92 & $1.39,2.66$ \\
\hline College/university + & $1 \cdot 12$ & $1.04,1.19$ & $2 \cdot 84$ & $2.63,3.05$ & 31.2 & $268 / 907$ & $2 \cdot 82$ & $2 \cdot 07,3.84$ \\
\hline $\begin{array}{l}P_{\text {trend }} \\
\text { Monthly incometł }\end{array}$ & & 001 & & 001 & & & & $<0.001$ \\
\hline$<20$ USD & 0.60 & $0.51,0.69$ & 2.00 & $1 \cdot 88,2 \cdot 13$ & $9 \cdot 6$ & $141 / 1199$ & 1.00 & \\
\hline $20-40$ USD & 0.82 & $0.72,0.91$ & $2 \cdot 22$ & $2 \cdot 10,2 \cdot 34$ & $15 \cdot 0$ & $209 / 1440$ & 1.57 & $1 \cdot 15,2 \cdot 14$ \\
\hline $41-60$ USD & 0.78 & $0.71,0.85$ & $2 \cdot 47$ & $2 \cdot 30,2.65$ & 18.5 & $191 / 1149$ & 1.94 & $1 \cdot 38,2 \cdot 74$ \\
\hline $61-80$ USD & 0.85 & $0.71,0.98$ & $2 \cdot 27$ & $2.08,2.47$ & $15 \cdot 9$ & 95/505 & 1.68 & $1.10,2.56$ \\
\hline $81+$ USD & 1.02 & $0.94,1.10$ & $2 \cdot 82$ & $2 \cdot 70,2.94$ & 28.4 & $379 / 1443$ & 3.00 & $2.20,4.09$ \\
\hline$P_{\text {trend }}$ & & 001 & & 001 & & & & $<0.001$ \\
\hline Women & & & & & & & & \\
\hline Age group & & & & & & & & \\
\hline $25-34$ years & 0.96 & $0.89,1.03$ & $2 \cdot 31$ & $2 \cdot 20,2 \cdot 42$ & $19 \cdot 3$ & $322 / 1731$ & 1.00 & \\
\hline $35-44$ years & 0.95 & $0.88,1.01$ & $2 \cdot 27$ & $2 \cdot 17,2 \cdot 37$ & $18 \cdot 8$ & $366 / 1912$ & 0.98 & $0.78,1.22$ \\
\hline $45-54$ years & 0.86 & $0.80,0.92$ & $2 \cdot 22$ & $2 \cdot 11,2 \cdot 32$ & $16 \cdot 9$ & $389 / 2120$ & 0.87 & $0.71,1.08$ \\
\hline $55-64$ years & 0.85 & $0.79,0.91$ & $2 \cdot 11$ & $2 \cdot 01,2 \cdot 22$ & $16 \cdot 4$ & $339 / 2053$ & 0.85 & $0.68,1.06$ \\
\hline$P_{\text {trend }}$ & & 006 & & 021 & & & & 0.093 \\
\hline Ethnicity† & & & & & & & & \\
\hline Kinh & 0.92 & $0.88,0.95$ & $2 \cdot 23$ & $2 \cdot 18,2 \cdot 29$ & $18 \cdot 1$ & $1129 / 6535$ & 1.00 & \\
\hline Non-Kinh & 0.92 & $0.82,1.02$ & 2.63 & $2.34,2.92$ & $20 \cdot 2$ & 283/1268 & $1 \cdot 10$ & $0.81,1.50$ \\
\hline$P$ & & 976 & & 007 & & & & 0.435 \\
\hline Residential areas $\dagger$ & & & & & & & & \\
\hline Urban & $1 \cdot 19$ & $1.14,1.25$ & $2 \cdot 28$ & $2 \cdot 22,2 \cdot 35$ & $24 \cdot 8$ & $667 / 2801$ & 1.00 & \\
\hline Rural & 0.80 & $0.75,0.84$ & $2 \cdot 24$ & $2 \cdot 16,2 \cdot 31$ & $15 \cdot 3$ & $749 / 5015$ & 0.62 & $0.53,0.72$ \\
\hline$P$ & & 001 & & 385 & & & & $<0.001$ \\
\hline Education levels $†$ & & & & & & & & \\
\hline$<$ Primary & 0.61 & $0.54,0.68$ & 1.87 & $1.78,1.95$ & 8.8 & 198/2124 & 1.00 & \\
\hline Primary & 0.82 & $0.76,0.88$ & $2 \cdot 18$ & $2 \cdot 09,2 \cdot 28$ & 14.4 & $307 / 2083$ & 1.64 & $1.17,2 \cdot 30$ \\
\hline Secondary & 0.96 & $0.88,1.05$ & $2 \cdot 40$ & $2 \cdot 28,2.52$ & 18.9 & $389 / 1928$ & $2 \cdot 15$ & $1.58,2.94$ \\
\hline Senior secondary & $1 \cdot 19$ & $1 \cdot 10,1 \cdot 27$ & $2 \cdot 42$ & $2 \cdot 27,2.57$ & 26.5 & $212 / 843$ & 3.03 & $2 \cdot 13,4.32$ \\
\hline College/university + & 1.39 & $1.28,1.51$ & $2 \cdot 70$ & $2 \cdot 54,2 \cdot 86$ & $36 \cdot 1$ & $308 / 821$ & $4 \cdot 14$ & $3.12,5.50$ \\
\hline$P_{\text {trend }}$ & & 001 & & 001 & & & & $<0.001$ \\
\hline $\begin{array}{l}\text { Monthly incomet‡ } \\
<20 \text { USD }\end{array}$ & & & & & & & & \\
\hline$<20$ USD & 0.61 & $0.55,0.68$ & 2.09 & $1 \cdot 96,2 \cdot 21$ & $10 \cdot 1$ & $215 / 1467$ & 1.00 & \\
\hline $20-40$ USD & 0.70 & $0.65,0.76$ & $2 \cdot 15$ & $2 \cdot 05,2 \cdot 25$ & $12 \cdot 4$ & $229 / 1623$ & 1.24 & $0.91,1.69$ \\
\hline $41-60$ USD & 0.89 & $0.82,0.96$ & $2 \cdot 32$ & $2 \cdot 18,2.47$ & $18 \cdot 6$ & $243 / 1317$ & 1.86 & $1.39,2.49$ \\
\hline $61-80$ USD & 1.04 & $0.93,1.15$ & $2 \cdot 32$ & $2 \cdot 17,2.48$ & $18 \cdot 7$ & $109 / 517$ & 1.87 & $1.29,2.72$ \\
\hline $81+$ USD & 1.25 & $1 \cdot 18,1.32$ & $2 \cdot 61$ & $2.50,2.72$ & 28.7 & $477 / 1626$ & 2.89 & $2 \cdot 16,3 \cdot 86$ \\
\hline$P_{\text {trend }}$ & & 001 & & 001 & & & & $<0.001$ \\
\hline
\end{tabular}

* $>5$ servings of fruit and vegetables/d in a typical week.

$\dagger$ Ethnicity, residential areas, education levels and income are adjusted for age.

$\ddagger$ Monthly household income per adult member. 
during 2009/2010 ${ }^{(12)}$, which reported values of daily consumption approximately $60 \mathrm{~g}(0.75$ servings $)$ of fruit and $157 \mathrm{~g}$ (1.97 servings) of vegetable leaves (no cruciferous, marrow, stems, allium or root plants). Our estimated proportions of respondents meeting dietary recommendations were lower than the results of a national survey conducted in Thailand in $2004(25 \cdot 4 \% \text { of men, } 27 \cdot 7 \% \text { of women })^{(21)}$, and a little lower than those reported in a pooled analysis of fifty-two mainly developing countries (22.4\% of men, $21.6 \%$ of women $)^{(3)}$. The proportions of the population reaching the recommended greater than or equal to two servings for fruit were lower, but the proportions of the population meeting the recommended greater than or equal to three servings of vegetables were higher, than those reported in the Thai survey ${ }^{(21)}$. Our estimated proportions of participants consuming at least five servings of fruit and vegetables for the sub-sample of Hanoi $25.8 \%$ of men, $28.9 \%$ of women) were lower than those from a previous

Table 3. Correlation of self-reported mean daily servings of fruit and vegetables, and the proportion of the population having at least five servings of fruit and vegetables daily, with body size and fatness

\begin{tabular}{|c|c|c|}
\hline & \multicolumn{2}{|c|}{ Partial Pearson's correlations $†$} \\
\hline & Men & Women \\
\hline \multicolumn{3}{|l|}{ BMI $\left(\mathrm{kg} / \mathrm{m}^{2}\right)$} \\
\hline Fruitł & $0.067^{\star \star \star}$ & $0 \cdot 111^{\star \star \star}$ \\
\hline Vegetables $\ddagger$ & $0.052^{\star \star \star}$ & $0.060^{\star \star \star}$ \\
\hline Fruit and vegetables $\ddagger$ & $0.062^{\star \star \star}$ & $0 \cdot 100^{\star \star \star}$ \\
\hline$\geq 5$ servings§ & $0.026^{*}$ & $0.084^{* \star *}$ \\
\hline \multicolumn{3}{|l|}{ Waist $(\mathrm{cm})$} \\
\hline Fruit $\ddagger$ & $0.069^{\star \star \star}$ & $0.153^{\star \star \star}$ \\
\hline Vegetables $\ddagger$ & $0.066^{\star \star \star}$ & $0.086^{\star \star \star}$ \\
\hline Fruit and vegetablesł & $0.074^{\star \star \star}$ & $0.135^{\star \star \star}$ \\
\hline$\geq 5$ servings§ & 0.024 & $0.123^{\star \star \star}$ \\
\hline \multicolumn{3}{|l|}{ Waist:hip ratio } \\
\hline Fruit‡ & $0.039^{* *}$ & $0.092^{\star \star *}$ \\
\hline Vegetables $\ddagger$ & $0.042^{\star \star}$ & $0.060^{\star \star *}$ \\
\hline Fruit and vegetables $\ddagger$ & $0.047^{\star \star \star}$ & $0.088^{\star \star \star}$ \\
\hline$\geq 5$ servings§ & 0.013 & $0.084^{* \star *}$ \\
\hline
\end{tabular}

* $P<0.05,{ }^{* *} P<0.01,{ }^{* * *} P<0.001$

$\dagger$ Partial Pearson's correlation adjusted for age, income and alcohol consumption.

$\ddagger$ Number of servings per day in a typical week.

$\S \geq 5$ servings of fruit and vegetables/d in a typical week. survey conducted in 2005 in Chililab community of Hanoi (36.5\% of men, $42.5 \%$ of women), but higher than those from another survey conducted in FilaBavi community of Hanoi (13\% of men, $13 \%$ of women) ${ }^{(13)}$. Our estimated proportions for the Can Tho sub-population (14.4\% of men, $12.4 \%$ of women) were lower than those from a previous survey conducted in Can Tho in 2005 (30.2\% of men, $26.5 \%$ of women) ${ }^{(14)}$.

Between-country differences in urbanisation were postulated to be a possible contributor to the variation in the countryspecific proportions of participants meeting the WHO recommendations in the pooled analysis of fifty-two mainly developing nations ${ }^{(3)}$. We found considerable variation in proportions of respondents meeting dietary recommendations, but between the provinces of a single country (online Supplementary Table S2). The present findings showed that the proportions of respondents reaching the WHO recommendations were high in the highly urbanised provinces of Hanoi and Can Tho. Our aggregate-level analyses supported this point. Within-province differences in urbanisation were also suggested as a potential explanation for the different estimates of proportions of participants meeting dietary recommendations in Chililab and FilaBavi communities of Hanoi ${ }^{(13)}$. A second source of heterogeneity is differences in timing of the surveys given seasonal availabilities of fruit and vegetables. It is well known that fruit and vegetable consumption patterns display seasonal variability, with higher consumption in the harvest season (the wet season in the present study) ${ }^{(22)}$. Our survey conducted in Can Tho was mainly in the dry season (March to August), whereas the 2005 Can Tho survey ${ }^{(14)}$ - which produced higher estimates - was conducted in the wet season (July to November). Even though the Chililab and FilaBavi surveys ${ }^{(13)}$ and our survey were all conducted in Hanoi at a similar time (June to November), the seasonal impacts on reporting may be variable because monthly rainfall in Hanoi, and the availability of fruit and vegetables, varies substantially from year to year.

The individual-level associations between fruit/vegetable intake and place of residence, education and income are in line with the findings of previous surveys in other developing countries $^{(3,13,21,23,24)}$. First, reported servings of fruit, fruit plus vegetables and proportions of participants meeting the WHO

Table 4. Correlations of the summary measures of fruit and vegetable consumption from eight provinces with their provincial mean values of the demographic, geographical and climatic factors $(n 8)$

\begin{tabular}{|c|c|c|c|c|c|c|c|c|}
\hline & \multicolumn{4}{|c|}{ Men } & \multicolumn{4}{|c|}{ Women } \\
\hline & Fruit† & Vegetables $†$ & Fruit and vegetables $†$ & $\geq 5$ servings $\ddagger$ & Fruit† & Vegetables $\dagger$ & Fruit and vegetables $†$ & $\geq 5$ servingsł \\
\hline Urban population§ & 0.30 & -0.31 & -0.14 & 0.24 & 0.54 & -0.37 & -0.14 & 0.20 \\
\hline Latitudell & 0.22 & $0.92^{*}$ & $0.80^{*}$ & 0.54 & 0.05 & $0.90^{*}$ & $0.78^{\star}$ & 0.58 \\
\hline Annual rainfall| & -0.09 & 0.27 & 0.18 & 0.30 & -0.29 & 0.18 & 0.06 & 0.19 \\
\hline Average temperature $\dagger$ & 0.20 & -0.43 & -0.27 & 0.05 & 0.21 & -0.48 & -0.34 & -0.12 \\
\hline Wet seasonfł & 0.44 & 0.26 & 0.36 & 0.40 & 0.58 & 0.33 & 0.46 & 0.52 \\
\hline
\end{tabular}

* $P<0.05$.

$\dagger$ Mean servings of fruit, vegetables, and fruit and vegetables combined.

$\ddagger$ Proportion of respondents consuming at least five servings of fruit and vegetables per day (\%).

$\S$ Proportion of respondents living in urban areas (\%).

II Latitude of the survey site of each province $\left({ }^{\circ}\right)$.

I Average rainfall of the survey site of each province $(\mathrm{mm})$.

†† Average temperature of the survey site of each province $\left({ }^{\circ} \mathrm{C}\right)$

$\ddagger \ddagger$ Proportion of respondents were interviewed in the wet season (average rainfall $>60 \mathrm{~mm}$ ). 
recommendations were higher in urban than in rural areas ${ }^{(21,24)}$. Although the majority of fruit and vegetables are cultivated in rural areas, they are transported to the markets in urban areas. Consequently, more fruit and vegetables are available to consumers in urban areas. Local markets in rural areas are more restricted in the variety of fruit and vegetables available for purchase ${ }^{(25)}$. Respondents living in urban areas had higher levels of education and income than those living in rural areas (data not shown), and our data support earlier findings in other developing countries ${ }^{(21,23,24)}$ that fruit and vegetable intake increases with levels of education and household income, but the association between fruit/vegetable intake and place of residence was independent of education and income status. This finding in individual analyses is supported by our aggregate-level analyses that provinces with higher proportions of urban population also had higher mean servings of fruit, and higher proportions of participants meeting the dietary recommendations, and is consistent with the results of previous studies $^{(21,26)}$. There was a remarkable similarity in reported intake of fruit and of vegetables for men and women of the same region, and particularly for men and women of similar body size.

In further assessment of the construct validity of the STEPS questionnaire for measuring fruit/vegetable intake in standard serving sizes, we examined the correlations between reported intake and body size/fatness. Somewhat unexpectedly, we found that reported servings of fruit, vegetables and fruit plus vegetables, as well as proportions of respondents who consumed at least five servings daily (women), were positively associated with body size/fatness, although the correlations were modest. These associations were independent of age, income, education, alcohol consumption, tobacco use and physical activity, but the STEPS questionnaire ${ }^{(8)}$ does not provide quantitative measures of total energy intake or even the energy intake of each food item. Only intake of fruit and vegetables was collected because the purpose of the STEPS methodology is to obtain small amounts of useful information on a regular and continuous basis when resources are limited. If those who ate more fruit and vegetables were also eating more of other high-energy foods, and total energy intake is a contributor to larger body size/fatness, adjusting for other energy sources would at least attenuate the positive associations found between fruit/vegetable consumption and body size/fatness and, if the cross-correlations with other energy sources were sufficiently strong, could unmask a protective association of fruit/ vegetable consumption with body size/fatness ${ }^{(27)}$

The findings also reflect the demographic, geographic and climatic characteristics of the country. The present findings of higher mean servings of vegetables in three northern-most provinces (Thai Nguyen, Hòa Bình and Hanoi) are consistent with the results of the national nutrition survey conducted in Vietnam $^{(28)}$. The survey results showed that vegetables form a larger part of the diet of persons living in the north than of those living in the south, where rice is an important component of diet. In addition, our higher mean servings of fruit in the highly urbanised provinces of Hanoi, Ho Chi Minh City and Can Tho are generally in line with the results of this national nutrition survey $^{(28)}$. Collectively, plausible associations found at the individual and aggregate levels suggest that intake reported in standard servings had some evidence of construct validity.

The present study has several strengths. First, the data were collected from a nationally representative survey of the Vietnamese population. The large sample allowed analyses stratified by ecological location, and the availability of data on other behavioural risk factors for NCD made it possible to take account of putative modifying, confounding and mediating factors. Second, the interviews were conducted by trained staff in accordance with standardised WHO protocols designed to minimise random error and bias, and using a culturally sensitive instrument that had been translated and back-translated. In addition, standardised serving sizes depicted by visual aids tailored to local types of fruit and vegetables were used in this survey to assist participants ${ }^{(6)}$.

However, this investigation has some limitations. First, although participation was high for a study with overnight fasting, blood sampling and nearly $2 \mathrm{~h}$ of on-site attendance, the possibility of non-participation bias cannot be discounted. If the mainly younger non-participants generally were absent for reasons of employment, and they ate greater than average quantities of fruit and vegetables by virtue of their active lives and incomes, the national estimates of fruit and vegetable consumption provided in Tables 1 and 2 would be slight underestimates. Information on fruit and vegetable consumption was self-reported. However, similar brief fruit and vegetable instruments have been validated and widely used in developed countries ${ }^{(29)}$ and, in our study, the reported numbers of 'standard servings' consumed allowed appropriate inferences. Second, information on fruit and vegetables was collected by provincial data collection teams. They were trained and supervised in the use of the standardised protocols by the same national and international supervisors. Nevertheless, inter-team variation cannot be excluded as a contributor to part of the differences found between geographical regions. Third, we found there was seasonal variation in the reporting of intake with higher mean values when reported in the wet season. This made almost no difference to our national estimates, because $<10 \%$ (1782/14706) of respondents were interviewed in the dry season, but our data suggest that a survey conducted in Vietnam in the wet season could produce mean estimates $4 \%$ (fruit) or $10 \%$ (vegetables) higher than a survey conducted in the dry season. Clearly, this is an issue to be considered when planning surveys.

\section{Conclusions}

In conclusion, approximately $80 \%$ of Vietnamese people aged 25-64 years did not meet WHO recommendations for daily consumption of at least five servings of fruit and vegetables. On the basis of the consistency of the data collected with other estimates and with geographical, climatic, demographic and socio-economic characteristics of the country and its population, the WHO STEPS instrument has construct validity for measuring fruit and vegetable intake in Vietnam, but with two issues identified. The issues were seasonal variation in reporting and a limitation on the usefulness of the information for associative analyses. 


\section{Acknowledgements}

The authors would like to thank The Atlantic Philanthropies Inc., USA for its financial support for data collection of the survey. The authors thank the Ministry of Health of the Socialist Republic of Vietnam and the provincial data collection teams for their contributions. The authors also thank Catrina Boon and Kate Butorac for their assistance with training and supervision of data collection teams.

This work was supported by a funding from the Atlantic Philanthropies Inc., USA (grant number G0015338). T. V. B. was supported by a Tasmania Graduate Research Scholarship. C. L. B. (1034482), V. S. (1061457) and K. S. (APP1072516) were supported by fellowships awarded by the National Health and Medical Research Council. V. S. (100089) and S. G. (PH 11H6047) were supported by fellowships awarded by the National Heart Foundation of Australia.

T. V. B. contributed to the conception and design of the study, conducted analyses and interpreted data, and drafted and revised the manuscripts. C. L. B. contributed to the conception and design of the study, supervised data collection, supervised the analyses and interpretation, and revised the manuscript for important intellectual content. K. N. L. contributed to the conception and design of the study, and revised the manuscript for important intellectual content. N. L. V. T. and B. Q. T. contributed to the conception and design of the study, supervised data collection and revised the manuscript for important intellectual content. P. O. contributed to the conception and design of the study, supervised data collection, conducted analyses and revised the manuscript for important intellectual content. V. S. and M. R. N. supervised data analyses and interpretation, and revised the manuscript for important intellectual content. T. B. A., S. T. H., H. N. P., M. H. T. and M. C. contributed to the conception and design of the study, supervised data collection and revised the manuscript for important intellectual content. K. S. contributed to the conception and design of the study, and revised the manuscript for important intellectual content. S. G. supervised data analyses and interpretation, and revised the manuscript for important intellectual content. All the authors approved the final manuscript.

The authors declare that there are no conflicts of interest.

\section{Supplementary material}

For supplementary material/s referred to in this article, please visit http://dx.doi.org/10.1017/S0007114516001690

\section{References}

1. Lim SS, Vos T, Flaxman AD, et al. (2012) A comparative risk assessment of burden of disease and injury attributable to 67 risk factors and risk factor clusters in 21 regions, 1990-2010: a systematic analysis for the Global Burden of Disease Study 2010. Lancet 380, 2224-2260.

2. World Health Organization (2009) Global Health Risks: Mortality and Burden of Disease Attributable to Selected Major Risks. Geneva: WHO.

3. Hall JN, Moore S, Harper SB, et al. (2009) Global variability in fruit and vegetable consumption. Am J Prev Med 36, 402-409.e5.
4. World Health Organization (2011) Global Status Report on Noncommunicable Diseases 2010. Geneva: WHO.

5. Thompson FE \& Subar AF (2013) Dietary assessment methodology. In Nutrition in the Prevention and Treatment of Disease, 3rd ed, [AM Coulston, CJ Boushey and MG Ferruzzi, editors]. Oxford: Elsevier Inc.

6. Agudo A (2005) Measuring intake of fruit and vegetables. http://www.who.int/dietphysicalactivity/publications/f\&v _ intake_measurement.pdf (accessed May 2015).

7. Coyne T, Ibiebele TI, McNaughton S, et al. (2005) Evaluation of brief dietary questions to estimate vegetable and fruit consumption - using serum carotenoids and red-cell folate. Public Health Nutr 8, 298-308.

8. World Health Organization (2008) WHO STEPS surveillance manual: the WHO STEPwise approach to chronic disease risk factor surveillance. http://www.who.int/chp/steps/manual/ en/ (accessed September 2015).

9. Kristal AR, Vizenor NC, Patterson RE, et al. (2000) Precision and bias of food frequency-based measures of fruit and vegetable intakes. Cancer Epidemiol Biomarkers Prev 9, 939-944.

10. Smith-Warner SA, Elmer PJ, Fosdick L, et al. (1997) Reliability and comparability of three dietary assessment methods for estimating fruit and vegetable intakes. Epidemiology $\mathbf{8}$, 196-201.

11. Field AE, Colditz GA, Fox MK, et al. (1998) Comparison of 4 questionnaires for assessment of fruit and vegetable intake. Am J Public Health 88, 1216-1218.

12. National Institute of Nutrition (2010) A Review of the Nutrition Situation in Vietnam 2009-2010. Hanoi: Medical Publishing House.

13. Kanungsukkasem U, Ng N, Hoang VM, et al. (2009) Fruit and vegetable consumption in rural adults population in INDEPTH HDSS sites in Asia. Glob Health Action 2, 35-43.

14. Pham HL, Au BT, Blizzard L, et al. (2009) Prevalence of risk factors for non-communicable diseases in the Mekong Delta, Vietnam: results from a STEPS survey. BMC Public Health 9, 291.

15. Bui TV, Blizzard L, Luong KN, et al. (2015) Declining prevalence of tobacco smoking in Vietnam. Nicotine Tob Res 17, 831-838.

16. WHO Expert Consultation (2004) Appropriate body-mass index for Asian populations and its implications for policy and intervention strategies. Lancet 363, 157-163.

17. Kish L (1995) Survey Sampling. New York, NY: John Wiley \& Sons.

18. Zou G (2004) A modified Poisson regression approach to prospective studies with binary data. Am J Epidemiol 159, 702-706.

19. World Health Organization (2003) Diet, Nutrition and the Prevention of Chronic Diseases. Report of a Joint WHO/FAO Expert Consultation. Geneva: WHO. http:// whqlibdoc.who.int/trs/WHO_TRS_916.pdf?ua=1 (accessed April 2015).

20. Peel MC, Finlayson BL \& McMahon TA (2007) Updated world map of the Köppen-Geiger climate classification. Hydrol Earth Syst Sci 11, 1633-1644.

21. Satheannoppakao W, Aekplakorn W \& Pradipasen M (2009) Fruit and vegetable consumption and its recommended intake associated with sociodemographic factors: Thailand National Health Examination Survey III. Public Health Nutr 12, 21922198.

22. Locke E, Coronado GD, Thompson B, et al. (2009) Seasonal variation in fruit and vegetable consumption in a rural agricultural community. J Am Diet Assoc 109, 45-51. 
23. Padrao P, Laszczynska O, Silva-Matos C, et al. (2012) Low fruit and vegetable consumption in Mozambique: results from a WHO STEPwise approach to chronic disease risk factor surveillance. Br J Nutr 107, 428-435.

24. Ruel MT, Minot N \& Smith L (2005) Patterns and determinants of fruit and vegetable consumption in Sub-Saharan Africa: a multi-country comparison. http://www.who.int/ entity/dietphysicalactivity/publications/f\&v_africa_economics.pdf (accessed May 2015).

25. Kosulwat V (2002) The nutrition and health transition in Thailand. Public Health Nutr 5, 183-189.

26. Shohaimi S, Welch A, Bingham S, et al. (2004) Residential area deprivation predicts fruit and vegetable consumption independently of individual educational level and occupational social class: a cross sectional population study in the Norfolk cohort of the European Prospective Investigation into Cancer (EPIC-Norfolk). J Epidemiol Community Health 58, 686-691.

27. Cole TJ (2005) Re: "why evidence for the fetal origins of adult disease might be a statistical artifact: the "reversal paradox" for the relation between birth weight and blood pressure in later life'. Am J Epidemiol 162, 394-395 author reply 5 .

28. National Institute of Nutrition (2003) 2000 General Nutrition Survey. Hanoi: Medical Publishing House.

29. Kim DJ \& Holowaty EJ (2003) Brief, validated survey instruments for the measurement of fruit and vegetable intakes in adults: a review. Prev Med 36, 440-447. 